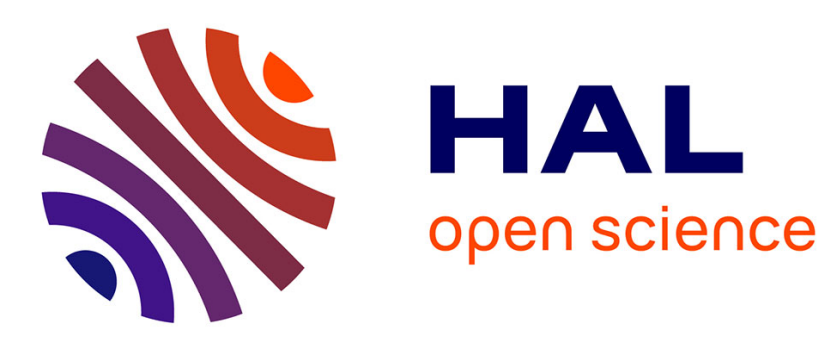

\title{
Predictive Current Control for an Induction Motor
}

\author{
Jean-Marie Rétif, Xuefang Lin-Shi, Florent Morel
}

\section{To cite this version:}

Jean-Marie Rétif, Xuefang Lin-Shi, Florent Morel. Predictive Current Control for an Induction Motor. IEEE PESC, Jun 2008, Rhodes, Greece. pp.3463-3468, 10.1109/PESC.2008.4592491 . hal-00374680

\section{HAL Id: hal-00374680 https://hal.science/hal-00374680}

Submitted on 3 Jun 2009

HAL is a multi-disciplinary open access archive for the deposit and dissemination of scientific research documents, whether they are published or not. The documents may come from teaching and research institutions in France or abroad, or from public or private research centers.
L'archive ouverte pluridisciplinaire HAL, est destinée au dépôt et à la diffusion de documents scientifiques de niveau recherche, publiés ou non, émanant des établissements d'enseignement et de recherche français ou étrangers, des laboratoires publics ou privés. 


\title{
Predictive Current Control for an Induction Motor
}

\author{
Jean-Marie Rétif, Xuefang Lin-Shi, Florent Morel \\ AMPERE -INSA de LYON \\ Bâtiment Léonard de Vinci \\ 21 avenue Jean Capelle \\ 69621 Villeurbanne Cedex \\ France \\ Email : xuefang.shi@insa-lyon.fr \\ Telephone : +334 724381 77- Fax : +334 72438530
}

\begin{abstract}
This paper presents a Predictive Current Control (PCC) strategy applied to an Induction Motor (IM) drive. In contrast to conventional vector control, where the inverter is not taken into account by the controller, the PCC considers the state of the inverter as a discrete control variable. Based on a simplified state space model of the IM and the inverter, the proposed control scheme calculates the state vector evolution direction in the $d$ - and q-reference frame for all possible switching states of the inverter. The switching state which minimizes a given cost function is selected and is applied during an adapted duration which is calculated for each computation cycle. As the control requires the knowledge of the instantaneous rotor fluxes and in order to improve the control robustness, a reduced-order extended high gain observer is proposed for estimation of rotor fluxes and inverse rotor time constant. The simulation results validate the observer. The controller is implemented on a $5.5 \mathrm{~kW}$ IM drive with a Digital-Signal-Processor (DSP) on a DSpace1103 board. Experimental results show the effectiveness and the performances of the proposed control.
\end{abstract}

Keywords-Predictive current control; induction motor; inverter; high gain observer.

\section{INTRODUCTION}

In AC-drive systems, fast current and torque responses are necessary. The development of high performance controls for AC-machine drives has motivated considerable attention in recent years. Many studies are reported for current controls [1-3].

The main objective of the current control is to ensure the tracking of the desired stator currents in a transient interval as short as possible. There are different strategies for current controllers. The main ones including linear control, hysteresis control, and predictive control are discussed in [4]. Among them, a widely used scheme for high performance is the predictive control. The method presented [5] and [6] uses Model Predictive Control (MPC) theory to determine the optimal set of switching states with a prediction horizon of 3 , but the real-time constraint is great due to the complexity of MPC algorithm. The approach presented here consists in using a simplified model in the $d-q$ rotor flux reference frame in order to predict the future value of the state variables for all possible inverter switching states. A cost function is evaluated for each of these configurations. The switching state which minimizes this cost function is selected and applied during a calculated duration. In [3] and [7], a similar approach is applied for a $R-L$ load in the $\alpha-\beta$ stator reference frame. In this reference frame, the future current references are unknown. The Lagrange extrapolation formula is used to predict the future reference current. In [8] and [9], very good results with this control are obtained for synchronous machine drives. Few experimental results are reported for induction motor. In this paper, the case of induction motor is discussed. One of difficulties for IM control is the estimation of the rotor fluxes and the stator pulsation. Indeed, the motor parameters, notably the rotor resistance value, can change with temperature. The incertitude on parameters induces estimation errors which can deteriorate the control quality. In order to achieve better system dynamic performance and robustness, the approach proposed in this paper consists in designing an extended observer allowing online estimation of the rotor fluxes and the inverse rotor time constant. Simulation studies show the feasibility of the approach. Experimental results are carried out on a real induction motor driver with a Digital-SignalProcessor for the proposed predictive current control.

\section{MODELS}

The IM is classically modelled by continuous state space equations written in the $d-q$ rotor flux reference frame.

$$
\dot{X}=A\left(\omega_{r}, \omega_{s}\right) X+B U
$$

with

$$
\begin{gathered}
X=\left[\begin{array}{llll}
\Phi_{r d} & \Phi_{r q} & I_{s d} & I_{s q}
\end{array}\right]^{t} ; \quad U=\left[\begin{array}{lll}
V_{s d} & V_{s q}
\end{array}\right]^{t} \\
A\left(\omega_{r}, \omega_{s}\right)=\left[\begin{array}{cccc}
-\sigma_{r} & \omega_{s}-\omega_{r} & \sigma_{r} L_{m} & 0 \\
-\left(\omega_{s}-\omega_{r}\right) & -\sigma_{r} & 0 & \sigma_{r} L_{m} \\
\sigma_{r} \beta & \beta \omega_{r} & -\lambda & \omega_{s} \\
-\beta \omega_{r} & \beta \sigma_{r} & -\omega_{s} & -\lambda
\end{array}\right] \\
B=\left[\begin{array}{cccc}
0 & 0 & \frac{1}{\sigma . L_{s}} & 0 \\
0 & 0 & 0 & \frac{1}{\sigma . L_{s}}
\end{array}\right]^{t}
\end{gathered}
$$




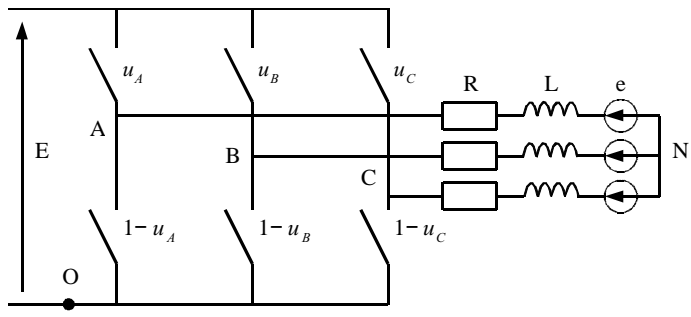

Figure 1. Simplified schematic of the IM-drive

$$
\begin{gathered}
\sigma_{r}=\frac{1}{T_{r}}=\frac{R_{r}}{L_{r}} ; \quad \sigma=1-\frac{L_{m}{ }^{2}}{L_{s} \cdot L_{r}} ; \quad \beta=\frac{1-\sigma}{\sigma \cdot L_{m}} \\
\lambda=\frac{1}{\sigma}\left(\frac{R_{s}}{L_{s}}+(1-\sigma) \cdot \sigma_{r}\right)
\end{gathered}
$$

where $I_{s d}$ and $I_{s q}$ are the $d$ - and $q$-axis stator currents, $\Phi_{r d}$ and $\Phi_{r q}$ are the $d$ - and $q$-axis rotor fluxes, $R_{s}$ and $R_{r}$ are the stator and the rotor phase resistances, $L_{s}, L_{r}$ and $L_{m}$ are the stator, rotor and mutual inductances, $\omega_{\mathrm{s}}$ and $\omega_{\mathrm{r}}$ are the stator and rotor angular velocity, $V_{s d}$ and $V_{s q}$ are the $d$ - and $q$-axis stator voltages.

For a sampling time $\Delta t$, the IM can be modelled by discrete-time equations

$$
X(t+\Delta t)=F\left(\omega_{r}, \omega_{s}, \Delta t\right) X(t)+G(\Delta t) U(t)
$$

where $F$ and $G$ are obtained by means of a Taylor expansion.

The stator voltages $V_{s d}$ and $V_{s q}$ depend on the switching states of the three-phase inverter (Fig.1). The switching states can take 8 possible configurations (Tab. I). It can be demonstrated that $V_{s d}$ and $V_{s q}$ can be expressed as functions of inverter leg states by using a rotation matrix (3).

$$
\begin{aligned}
{\left[\begin{array}{l}
V_{s d}(t) \\
V_{s q}(t)
\end{array}\right]=E \sqrt{\frac{2}{3}}\left[\begin{array}{cc}
\cos \theta_{r}(t) & \sin \theta_{r}(t) \\
-\sin \theta_{r}(t) & \cos \theta_{r}(t)
\end{array}\right] } \\
{\left[\begin{array}{rrr}
1 & -\frac{1}{2} & -\frac{1}{2} \\
0 & \frac{\sqrt{3}}{2} & -\frac{\sqrt{3}}{2}
\end{array}\right]\left[\begin{array}{l}
u_{A}(t) \\
u_{B}(t) \\
u_{C}(t)
\end{array}\right] }
\end{aligned}
$$

Among the 8 possible states of the inverter, two of them

TABLE I. INVERTER SWITCHING STATES

\begin{tabular}{|c|c|c|c|c|c|c|c|c|}
\hline $\mathrm{j}$ & 0 & 1 & 2 & 3 & 4 & 5 & 6 & 7 \\
\hline$u_{A}$ & 0 & 1 & 1 & 0 & 0 & 0 & 1 & 1 \\
\hline$u_{B}$ & 0 & 0 & 1 & 1 & 1 & 0 & 0 & 1 \\
\hline$u_{C}$ & 0 & 0 & 0 & 0 & 1 & 1 & 1 & 1 \\
\hline
\end{tabular}

(corresponding to $\mathrm{j}=0$ and $\mathrm{j}=7$ ) lead to the same output voltages ( $V_{s d}=V_{s q}=0$, free response). So, for the sake of simplicity, the case $\mathrm{j}=0$ will not be considered.

Finally, the model of the IM and its inverter can be written (4).

$$
X_{j}(t+\Delta t)=F\left(\omega_{r}, \omega_{s}, \Delta t\right) X(t)+G_{1}\left(\theta_{r}, \Delta t\right) u_{j}(t)
$$

where

$$
u_{j}(t)=\left[\begin{array}{lll}
u_{A_{j}}(t) & u_{B_{j}}(t) & u_{C_{j}}(t)
\end{array}\right]_{j=1, \cdots 7}^{t}
$$

\section{PREDICTIVE CURRENT CONTROL PRINCIPLE}

The proposed control consists in determining a configuration of the inverter and calculating its application time $\tau$ in order to track the desired reference states.

At each computation cycle, stator currents and angular position are measured. The rotor fluxes are obtained by an observer or an estimator. Like with field oriented control, the $d-q$ coordinate frame is supposed coinciding with the coordinate frame rotating synchronously with the rotor flux vector. The stator pulsation $\omega_{\mathrm{s}}$ can be deduced from $\Phi_{r d}$. Once the matrices $F\left(\omega_{r}, \omega_{s}, \Delta t\right)$ and $G_{1}\left(\theta_{r}, \Delta t\right)$ are calculated, the directions $d_{j}(t+\Delta t)=X_{j}(t+\Delta t)-X(t)$ can be predicted for the 7 possible control vector $u_{j}$ by using the model (4). For a desired reference state vector $X^{\#}$, the desired direction from the measured state can be calculated too $d^{\#}(t+\Delta t)=X^{\#}(t+\Delta t)-X(t)$.

The angle between directions $d_{j}(t+\Delta t)$ and $d^{\#}(t+\Delta t)$ is evaluated.

$$
\cos \theta_{j}=\frac{d^{\#}(t+\Delta t) \cdot d_{j}(t+\Delta t)}{\left|d^{\#}(t+\Delta t)\right|\left|d_{j}(t+\Delta t)\right|}
$$

During a short time $\tau$, the evolution of the state vector can be considered as a straight line and its amplitude can be considered proportional to the application time. The next application time $\tau$ during which the selected configuration will be applied can be calculated by (6):

$$
\tau=\frac{d^{\#}(t+\Delta t) \cdot d_{o p t}(t+\Delta t)}{\left|d_{o p t}(t+\Delta t)\right|\left|d_{o p t}(t+\Delta t)\right|} \Delta t
$$

On the one hand, in order to respect the assumption that state variable trajectories in the state space are straight lines, $\tau$ must be bounded above by $\tau_{\max }$. On the other hand, due to technology limitations of converter and/or computation unit performance (computation cycle duration), $\tau$ must be bounded below by a minimum application time $\tau_{\min }$ which is larger than the duration of the algorithm calculation.

The principle of predictive control for IM drive is summarized in Fig. 2. 


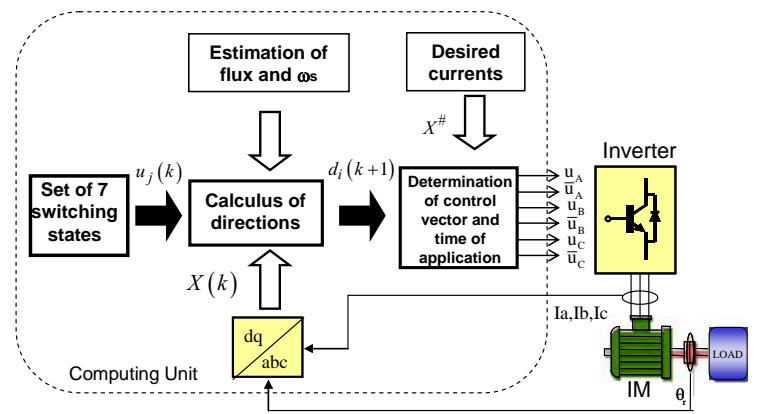

Figure 2. PCC principle for IM driver

IV. REDUCED ORDER EXTEND HIGH GAIN OBSERVER

The proposed predictive control requires the knowledge of the rotor fluxes which are not usually measurable in practice. An observer for estimation of the rotor fluxes is necessary. As previously mentioned, the control quality depends on the model accuracy. A variation of the rotor resistance (which varies with temperature) can induce a performance degradation of the system. So an extended observer which allows an on-line estimation of fluxes and inverse rotor time constant $\sigma_{r}=\frac{R_{r}}{L_{r}}$ is proposed. As currents are measured, they can be extracted from the state vector of the observer. The extended reduced order state space equation (7) is used.

$$
\begin{aligned}
& \dot{X}_{r}=f_{r}\left(X_{r}\right)+g_{r}\left(X_{r}, U_{r}\right) \\
& y_{r}=h_{r}\left(X_{r}\right) \\
& X_{r}=\left[\begin{array}{lll}
\Phi_{r d} & \Phi_{r q} & \sigma_{r}
\end{array}\right]^{t}=\left[\begin{array}{lll}
x_{r 1} & x_{r 2} & x_{r 3}
\end{array}\right]^{t} \\
& U_{r}=\left[\begin{array}{ll}
I_{s d} & I_{s q}
\end{array}\right]^{t} \\
& y_{r}=\left[\begin{array}{ll}
\Phi_{r d e} & \Phi_{r q e}
\end{array}\right]^{t} \\
& f_{r}\left(x_{r}\right)=\left\{\begin{array}{l}
-x_{r 1} x_{r 3}+\left(\omega_{s}-\omega_{r}\right) x_{r 2} \\
-\left(\omega_{s}-\omega_{r}\right) x_{r 2}-x_{r 2} x_{r 3} \\
0
\end{array}\right. \\
& g_{r}\left(X_{r}, U_{r}\right)=\left\{\begin{array}{l}
L_{m} x_{r 3} u_{r 1} \\
L_{m} x_{r 3} u_{r 2} \\
0
\end{array}\right.
\end{aligned}
$$

As the system (7) is nonlinear, a high gain nonlinear observer [10] is realized.

$$
\dot{\hat{X}}_{r}=f_{r}\left(\hat{X}_{r}\right)+g_{r}\left(\hat{X}_{r}\right) U_{r}+G\left(\hat{X}_{r}, U_{r}, y_{r}\right)\left(y_{r}-h_{r}\left(\hat{X}_{r}\right)\right)(8)
$$

Unlike linear observers, the gain matrix $G\left(\hat{X}_{r}, U_{r}, y_{r}\right)$ is not a constant but a nonlinear function of $\hat{X}_{r}, U_{r}$ and $y_{r} \cdot y_{r}$ is obtained from current and the stator voltage measurements and by solving the differential equations (9).

$$
\left\{\begin{array}{l}
\frac{d \Phi_{r d e}}{d t}=\frac{L_{r}}{L_{m}}\left(V_{s d}-R_{s} I_{s d}\right)-\frac{\sigma L_{r} L_{s}}{L_{m}}\left(\frac{d I_{s d}}{d t}-\omega_{s} I_{s q}\right)+\omega_{s} \Phi_{r q e} \\
\frac{d \Phi_{r q e}}{d t}=\frac{L_{r}}{L_{m}}\left(V_{s q}-R_{s} I_{s q}\right)-\frac{\sigma L_{r} L_{s}}{L_{m}}\left(\frac{d I_{s q}}{d t}+\omega_{s} I_{s d}\right)-\omega_{s} \Phi_{r d e}
\end{array}\right.
$$

The matrix $G\left(\hat{X}_{r}, U_{r}, y_{r}\right)$ is designed as follows so that the error dynamic is asymptotically stable.

The coordinate transformation (10) is introduced.

$$
\left[\begin{array}{l}
z_{r 1} \\
z_{r 2} \\
z_{r 3}
\end{array}\right]=\Gamma\left(X_{r}\right)=\left[\begin{array}{l}
h_{r 1} \\
L_{f} h_{r 1} \\
h_{r 2}
\end{array}\right]=\left[\begin{array}{l}
x_{r 1} \\
-x_{r 1} x_{r 3}+\left(\omega_{s}-\omega_{r}\right) x_{r 2} \\
x_{r 2}
\end{array}\right]
$$

With this transformation the state equation (7) is the sum of a linear term plus a non linear one. Furthermore the outputs are linear functions of the new state $Z_{r}=\left(z_{r 1}, z_{r 2}, z_{r 3}\right)^{t}(11)$.

$$
\left[\begin{array}{c}
\dot{z}_{r 1} \\
\dot{z}_{r 2} \\
\dot{z}_{r 3}
\end{array}\right]=\underbrace{\left[\begin{array}{cc}
A_{1} & 0_{2 \times 1} \\
0_{1 \times 2} & A_{2}
\end{array}\right]}_{A_{r}}\left[\begin{array}{c}
z_{r 1} \\
z_{r 2} \\
z_{r 3}
\end{array}\right]+\underbrace{\left[\begin{array}{c}
0 \\
\varphi_{1}\left(Z_{r}, u_{r}\right) \\
\varphi_{2}\left(Z_{r}, u_{r}\right)
\end{array}\right]}_{\varphi_{r}}
$$

$$
\begin{gathered}
y_{r}=\underbrace{\left[\begin{array}{cc}
C_{1} & 0_{1 \times 1} \\
0_{1 \times 2} & C_{2}
\end{array}\right]}_{C_{r}}\left[\begin{array}{c}
z_{r 1} \\
z_{r 2} \\
z_{r 3}
\end{array}\right] \\
A_{1}=\left[\begin{array}{ll}
0 & 1 \\
0 & 0
\end{array}\right] ; \quad A_{2}=0 ; \quad C_{1}=\left[\begin{array}{cc}
1 & 0
\end{array}\right] ; \quad C_{2}=1 \\
\varphi_{1}\left(Z_{r}, U_{r}\right)=\frac{\left(\omega_{s}-\omega_{r}\right) z_{r 3}-z_{r 2}}{z_{r 1}}\left[\left(\omega_{s}-\omega_{r}\right) z_{r 3}-z_{r 2}\right] \\
{\left[\begin{array}{l}
-\left(\omega_{s}-\omega_{r}\right) z_{r 3}-\frac{\left(\omega_{s}-\omega_{r}\right) z_{r 3}-z_{r 2}}{z_{r 1}} L_{m} u_{r 1} \\
+
\end{array}\right.} \\
\varphi_{2}\left(\omega_{s}-\omega_{r}\right) \varphi_{2}\left(\Gamma, U_{r}\right) \\
+\frac{\left(\omega_{s}-\omega_{r}\right) z_{r 3}-z_{r 2}}{z_{r 1}} L_{m} u_{r 2}
\end{gathered}
$$

In this way, the dynamic system (12) is an exponential observer for the system (11), where $\Lambda$ is defined in (13).

$$
\begin{gathered}
\dot{\hat{Z}}_{r}=A_{r}\left(\hat{Z}_{r}\right)+\varphi_{r}\left(\hat{Z}_{r}, U_{r}\right)+\Lambda^{-1} K\left(y_{r}-C_{r} Z_{r}\right) \\
\Lambda=\left[\begin{array}{ccc}
T_{1} & 0 & 0 \\
0 & T_{1}^{2} & 0 \\
0 & 0 & T_{2}
\end{array}\right] \text { with } T_{1,2}>0
\end{gathered}
$$


TABLE II.

PARAMETERS OF THE INDUCTION MOTOR

\begin{tabular}{|l|l|l|l|}
\hline $\mathrm{P}=5.5 \mathrm{~kW}$ & $\mathrm{U}=220 \mathrm{~V}$ & $\mathrm{I}=20.2 \mathrm{~A}$ & $\mathrm{p}=2$ \\
\hline$f=50 \mathrm{~Hz}$ & $\Omega=1420 \mathrm{rpm}$ & $\begin{array}{l}\mathrm{J}=0.248 \\
\mathrm{~kg} . \mathrm{N} . / \mathrm{m}^{2}\end{array}$ & $\begin{array}{l}\mathrm{d}=0.05 \\
\text { N.m.s } / \mathrm{rad}\end{array}$ \\
\hline$R_{s}=1 \Omega$ & $R_{r}=1.179 \Omega$ & $L_{s}=0.1197 \mathrm{H}$ & $L_{r}=0.116 \mathrm{H}$ \\
\hline$L_{f}=0.0037 \mathrm{H}$ & $L_{m}=0.116 \mathrm{H}$ & & \\
\hline
\end{tabular}

$K$ is a gain matrix which is chosen that $\left(A_{r}-K C_{r}\right)$ is Hurwitz. The dynamic of observer (12) can be adjusted through $K$ and $T_{1,2}$.

From (10) to (12), going back to the original system of coordinates, an observer for system (7) is then given by (14).

$$
\begin{array}{r}
\dot{\hat{X}}_{r}=f_{r}\left(\hat{X}_{r}\right)+g_{r}\left(\hat{X}_{r}\right) u_{r}+\left[\frac{\partial \Gamma\left(\hat{X}_{r}\right)}{\partial \hat{X}_{r}}\right]^{-1} \Lambda^{-1} K\left(y_{r}-h_{r}\left(\hat{X}_{r}\right)\right) \\
\text { with }\left[\frac{\partial \Gamma\left(x_{r}\right)}{\partial x_{r}}\right]=\left[\begin{array}{ccc}
1 & 0 & 0 \\
-x_{r 3} & \left(\omega_{s}-\omega_{r}\right) & -x_{r 1} \\
0 & 1 & 0
\end{array}\right]
\end{array}
$$

This Jacobian matrix is invertible if $x_{r 1}=\Phi_{r d} \neq 0$.

\section{Simulation RESUltS}

In order to verify the feasibility of the proposed high gain observer, the simulation on SIMULINK from Mathwork has been carried out for a $5.5 \mathrm{~kW}$ induction motor. The high gain observer is implanted in a S_function using $C$ language.

For the hybrid control, a first order Taylor expansion is retained to approximate the model (4). A second or third order expansion can be developed for the simulation, but it will increase the complexity and the computation duration for real-time implementation.

The maximum application time $\tau_{\max }$ has been limited to $100 \mu$ s which can guarantee the rectilinearity of state trajectories. The minimum application time $\tau_{\min }$ is set to $10 \mu \mathrm{s}$.

The current references are generated by a speed control loop. A discrete-time PI controller determined by pole assignment is used. The closed-loop dynamic corresponds to a discrete-time first order with a time constant of $0.1 \mathrm{~s}$.

The nominal parameters of the induction motor are given in the Tab. II. The rotor flux references are fixed to nominal value $(1.14 \mathrm{~Wb})$ for $\Phi_{r d}$ and $0 \mathrm{~Wb}$ for $\Phi_{r q}$.

In order to evaluate the observer performances and effectiveness, the comparisons between the observed state variables and the simulated ones have been realized for several operating conditions.

Fig.3 to 6 show the simulation results for a step input of the speed reference $\Omega_{r}^{\#}$ from 0 to $500 \mathrm{rpm}$. In order to verify the inverse rotor time constant tracking, the simulation is realized with $50 \%$ variation of the nominal rotor resistance $\left(R_{r}=1.5 R_{r n}\right)$.

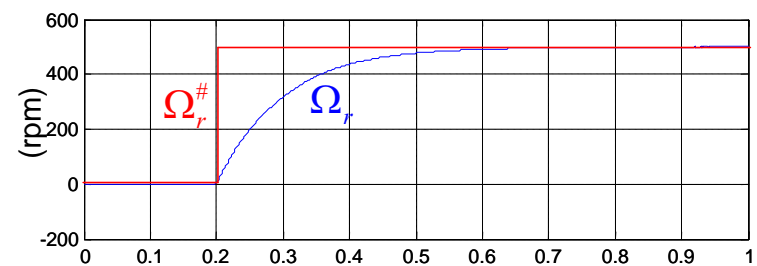

$\mathrm{t}(\mathrm{s})$

Figure 3. Evolution of the speed during a transition from $\Omega_{r}^{\#}=0 \mathrm{rpm}$ to $\Omega_{r}^{\#}=500 \mathrm{rpm}$

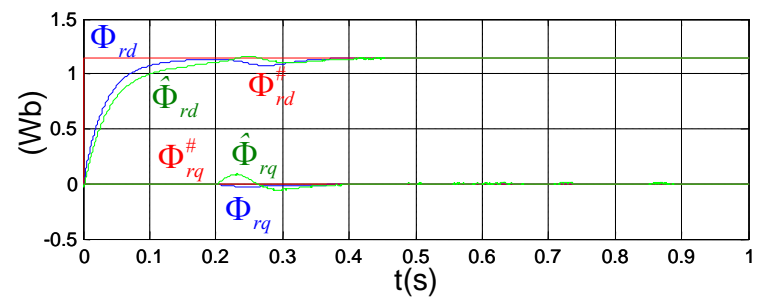

Figure 4. Simulated and observed fluxes during a transition from $\Omega_{r}^{\#}=0 \mathrm{rpm}$ to $\Omega_{r}^{\#}=500 \mathrm{rpm}$

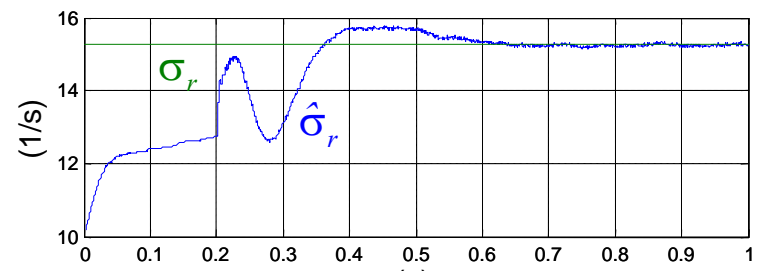

$\mathrm{t}(\mathrm{s})$

Figure 5. Simulated and observed inverse rotor constant time during a transition from $\Omega_{r}^{\#}=0 \mathrm{rpm}$ to $\Omega_{r}^{\#}=500 \mathrm{rpm}$

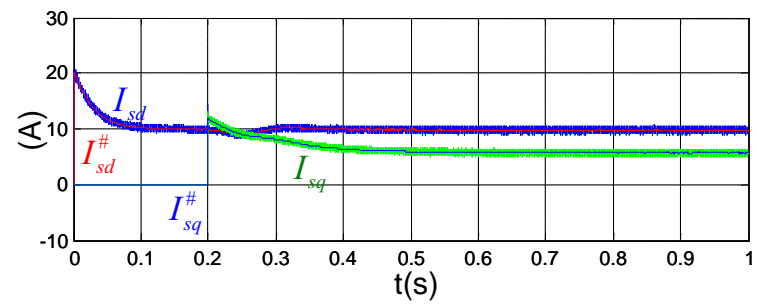

Figure 6. Evolution of the currents during a transition from

$$
\Omega_{r}^{\#}=0 \mathrm{rpm} \text { to } \Omega_{r}^{\#}=500 \mathrm{rpm}
$$

One can see that the estimated values of fluxes (Fig. 4) and inverse rotor time constant (Fig.5) converge very well to their simulated values.

Current ripples can be noted on Fig. 6. This is because the predictive current control applies only one converter configuration by cycle. As there are only seven possible configurations, the corresponding state vectors could not reach exactly the reference point. When the state is close to the reference point, as $\tau$ is limited to $\tau_{\min }$, the state vector could then oscillate around the reference point. The smallest the $\tau_{\min }$ value, the lowest the current ripple. 


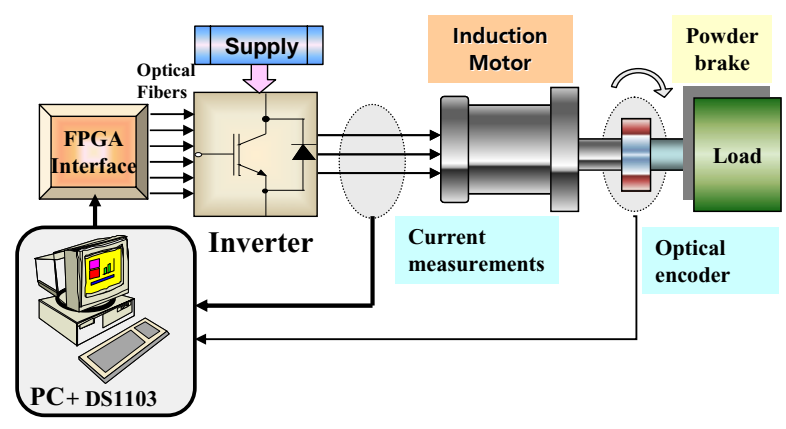

Figure 7. Experimental set-up

\section{EXPERIMENTAL RESULTS}

The experiment study was conducted with the equipment pictured in Fig. 7.

The IM used is the same as for simulations. A commercial $15 \mathrm{~kW}$ three-phase inverter, three LEM current sensors and a 2000-pulse incremental encoder are used.

The control algorithm is implemented in C language on a DSpace DS1103 board. The digital I/O port is used to control the configuration of the inverter. A FPGA interface is added to perform dead times (set to $5 \mu \mathrm{s}$ ) in inverter legs. At the moment of the paper redaction, the proposed high gain observer is not yet implemented for real-time operation. So the fluxes and the stator pulsation are estimated by the classical way using nominal parameters. The maximum and minimum times of application are kept as for the simulations.

Firstly the rotor is locked in order to show torque dynamic without the influence of speed.

Experimental results in Fig. 8 correspond to a transient response from a negative current reference ( $I_{s q}^{\#}=-16 A$ ) to a positive reference $\left(I_{s q}^{\#}=16 A\right)$ while $I_{s d}^{\#}$ is set to $10 A$, $\Phi_{r d}^{\#}=1.14 \mathrm{~Wb}$ and $\Phi_{r q}^{\#}=0 \mathrm{~Wb}$. This experiment corresponds to a torque reference step from $-37 \mathrm{Nm}$ to $37 \mathrm{Nm}$ (Fig. 9) which is equivalent to a nominal electromagnetic torque inversion for this machine. It can be seen that the steady-state operation is reached without any overshoot neither for $I_{s d}$ nor for $I_{s q}$. Moreover, the time response is lower than $700 \mu \mathrm{s}$.

Secondly the speed control loop is added. The discretetime PI controller used is the same as for simulations. Fig.10 corresponds to an evolution of the motor speed from $-500 \mathrm{rpm}$ to $500 \mathrm{rpm}$ for a load torque of about 5 $\mathrm{Nm}$. The speed dynamic is respected but it does not correspond to a first order dynamic. This can be explained by the mechanical model error due to parameter incertitude and frictions.

The transient evolution of the currents in the d-q reference frame (Fig. 11) shows that the step change of speed produces a change of the current $I_{s q}$ from $-2.5 \mathrm{~A}$ to $20 \mathrm{~A}$. The current $I_{s q}$ is maintained at $10 \mathrm{~A}$ without any cross-coupling effect. Current ripples can be found as on simulation.

Due to the PI speed controller, the torque reference overtakes the rated torque during the transient operation. Then one can see over currents during this time interval.
During steady state operation, phase current shapes are almost sinusoidal with low-level ripples.

\section{CONCLUSION}

In this paper, a predictive current control applied to an induction motor has been presented and validated on an

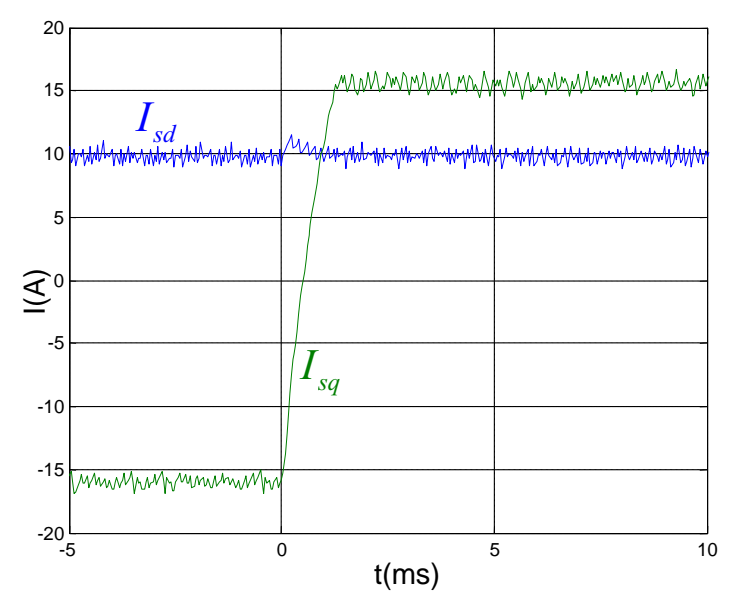

Figure 8. d- and q- axis current waveforms during transient from $I_{s q}^{\#}=-16 A$ to $I_{s q}^{\#}=16 A$

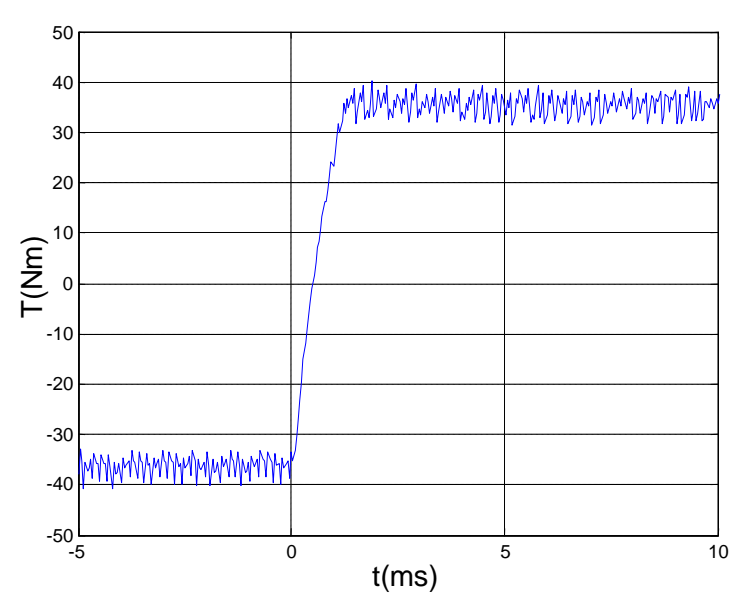

Figure 9. Estimated torque evolution during a transient from $I_{s q}^{\#}=-16 A$ to $I_{s q}^{\#}=16 A$

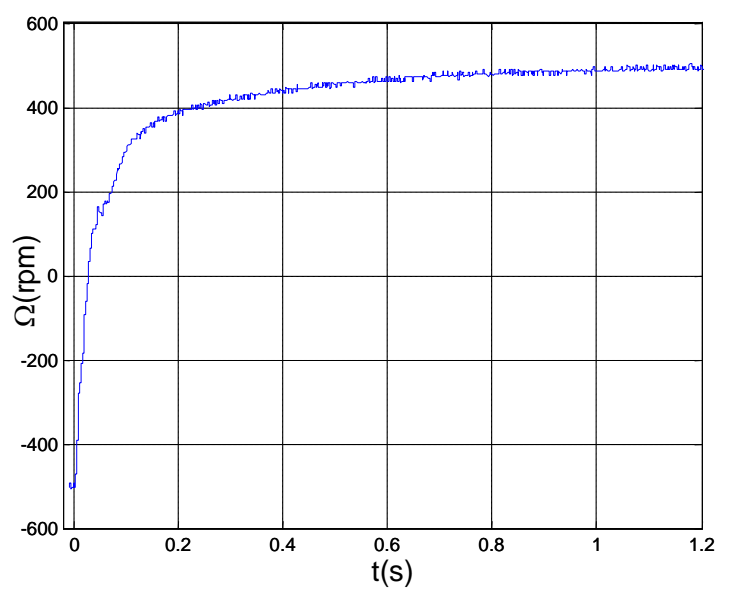

Figure 10. Evolution of the speed during a transient from -500 rpm to $500 \mathrm{rpm}$ 
experimental test bench. The fast dynamic performance is proved. A new reduced order high-gain observer is proposed to estimate the rotor fluxes and the inverse rotor time constant in order to compensate some parameter variations. The observer has been validated on simulation. This shows its feasibility and effectiveness. It can be noted that the proposed control requires high performance hardware for real-time implementation. The switching frequency is not fixed. These drawbacks can be suppressed by choosing more than one converter configuration (multi-step predictive current control) in a fixed switching frequency. Further work will be carried out on multi-step PCC with observer implementation on real-time.

\section{REFERENCES}

[1] V. Ambrozic, R. Fiser and D. Nedeljkovic, "Direct current control-a new current regulation principle”, IEEE Trans. Power Electronics, vol 18, no. 1, pp. 485-503, January 2003.

[2] M. Pacas and J. Weber, "Predictive direct torque control for the PM-synchronous machine”, IECON '03: 29th Annual Conference of the IEEE Industrial Electronics Society, vol. 2, pp. 1249-1254. Roanoke (USA), November 2003.

[3] J. Rodriguez, J. Pontt, C. Silva, M. Salgado, S. Rees, U. Ammann, P. Lezana, R. Huerta and P. Cortes, "Predictive control of threephase inverter”, IEE Electronic Letters, vol 40, issue 9, pp. 561563, April 2004.

[4] H. Le-Huy, K. Slimani and P.Viarouge, "Analysis and Implementation of a Real-Time Predictive Current Controller for Permanent-Magnet Synchronous Machine”, IEEE Transactionl of Industrial Electronics, vol 41, nº 1, pp. 110-117, February 1994.

[5] A. Linder and R. Kennel, "Model Predictive Control for Electrical Drives", PESC'2005: 36th IEEE Power Electronics Specialists Conference. pp. 1793 - 1799. Recife (Brazil). June 2005.

[6] A. Linder and R. Kennel, "Direct model predictive control - a new direct predictive control strategy for electrical drives”, EPE 2005: 11th European Conference on Power Electronics and Applications, Dresden (Germany). September 2005.

[7] J. Rodriguez, J. Pontt, C. Silva, P. Correa, P. Lezana, P. Cortes and U. Ammann, "Predictive current control of a voltage source inverter", IEEE Trans. Ind. Electron, vol 54, n 1, pp. 495-503, February 2007.

[8] X. Lin-Shi, F. Morel, A. Llor, B. Allard and J.M. Rétif, "Implementation of hybrid control for motor drives", IEEE Transactions on Industrial Electronics, Vol. 54, $\mathrm{n}^{\circ} 4$, pp. 19461952, August 2007.

[9] J.M. Rétif, X. Lin-Shi, A. Llor, F. Morand, "New hybrid direct torque control for a winding rotor synchronous machine", PESC'2004: 35th IEEE Power Electronics Specialists Conference, pp. 1438-1442, Aachen, Germanye, June 2004.

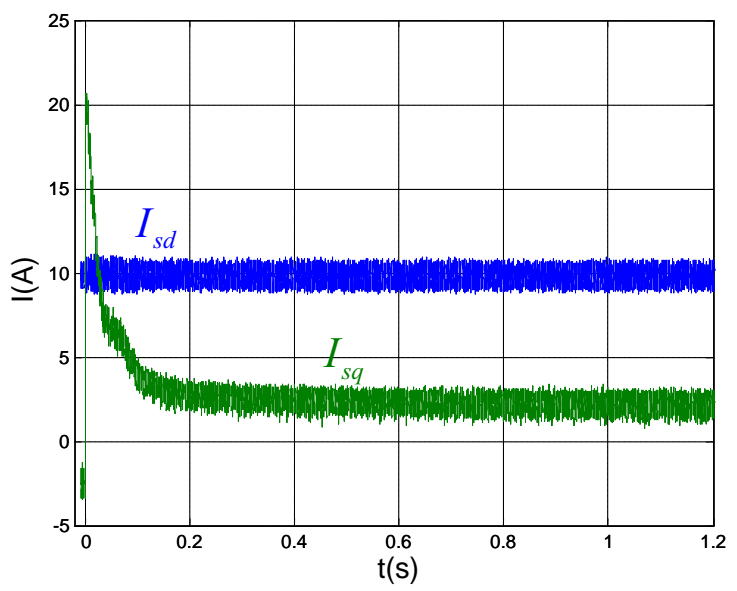

Figure 11. Evolution of the d- and q- axis currents during a speed transient from -500 rpm to $500 \mathrm{rpm}$

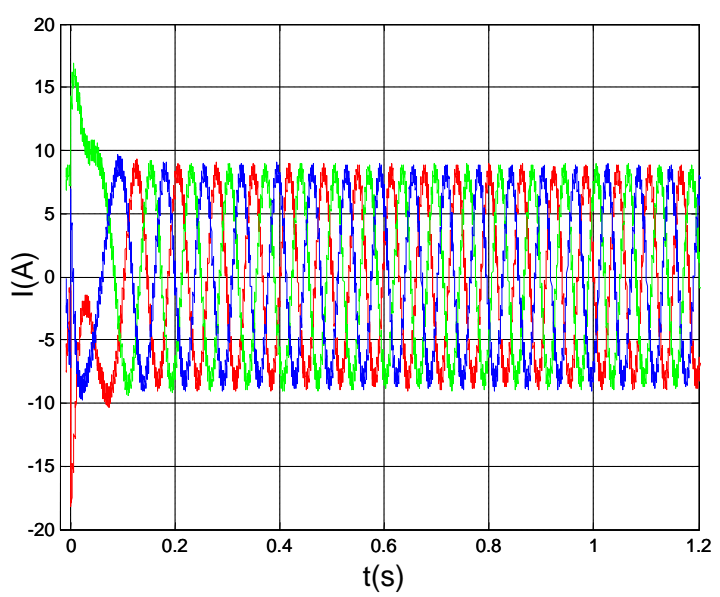

Figure 12. Evolution of the stator currents during a transient from $500 \mathrm{rpm}$ to $500 \mathrm{rpm}$

[10] G. Bornard, H.Hammouri, "A high gain observer for a class of uniformly observable systems", Proc. of the 30th Conference on Decision and Control (CDC), pp. 1494-1496, Brighton, England, December 1991. 